\title{
Política e Gestão no Controle do Câncer
}

doi: https://doi.org/10.32635/2176-9745.RBC.2021v67n4.2534

\author{
Cancer Control Policy and Management \\ Política y Gestión de Control del Cáncer
}

Jeane Tomazelli ${ }^{1}$

A atual Política Nacional para a Prevenção e Controle do Câncer (PNPCC) ${ }^{1}$ é simultaneamente produto e parte integrante de uma série de normativas que buscam organizar as açóes e serviços de saúde para assegurar ao cidadáo o acesso universal e igualitário à promoção, à proteção e à recuperação. Sob o prisma da Reforma Sanitária, pautado na concepção de saúde como direito social, busca-se construir um Sistema Único de Saúde (SUS) no qual os valores e crenças estruturantes da sociedade são a igualdade e a equidade ${ }^{2}$.

As necessidades de saúde da populaçáo, singularizadas pelos determinantes e condicionantes sociais e pelas desigualdades na oferta de serviços, respaldam a necessidade de organização das Redes de Atenção à Saúde (RAS) de forma regionalizada e hierarquizada, assegurando a integralidade do cuidado de forma igualitária. Para tanto, o planejamento territorial, o conhecimento dos instrumentos de gestâo e de pactuação, o embasamento técnico e a habilidade de articulação entre os diferentes níveis de gestão fazem-se necessários.

Entender que a PNPCC deve induzir à promoção, à proteção e à recuperação da saúde traz a necessidade de açôes de avaliação dos seus resultados. Logo, a sua implementação deve estar acompanhada de estudos de avaliação para prover informaçôes sobre a sua efetividade e a identificação dos pontos de fragilidades. Tais estudos devem fornecer elementos que expliquem os resultados, permitindo as adequaçóes necessárias ${ }^{3}$. Ao avaliar a política, ou os componentes de seus programas, é preciso delimitar a abrangência do problema, estabelecer um modelo teórico e definir indicadores que estabeleçam um diagnóstico da situação e subsidiem os gestores nas decisóes. É necessário que essa prática se insira em uma rotina contínua de avaliação, constituindo o monitoramento e possibilitando acompanhar a sua implementação.

O processo de avaliação é complexo, não imparcial e com diferentes caminhos avaliativos, o que contribuiu para a elaboração de um guia de avaliação das doenças crônicas não transmissíveis (DCNT) $)^{4}$ o qual sistematizou alguns estudos da área e forneceu exemplos de avaliaçôes realizadas. Dessa forma, o guia constitui importante referência para os estudos de avaliação em oncologia. Entre as principais referências teóricas em avaliação e saúde, estão Donabedian ${ }^{5}$ e Habicht et al. ${ }^{6}$ : o primeiro propóe avaliar indicadores que mensurem estrutura, processo e resultado; os outros sugerem indicadores de oferta, utilizaçáo, cobertura e impacto (resultado). A diferença entre esses autores está no enfoque teórico ${ }^{4}$ : estudos voltados para avaliação em saúde pública estão alinhados com Habicht et al. ${ }^{6}$, enquanto aqueles que focam avaliação de serviços seguem o modelo teórico de Donabedian ${ }^{5}$. Assim, Habicht et al. ${ }^{6}$ oferecem uma abordagem teórica dirigida a grupos populacionais, além de fornecerem três tipos de inferência causal (adequação, plausibilidade, probabilidade) para esses modelos de estudo ${ }^{4,7}$.

Estudos que avaliem a política e sua efetividade auxiliam a gestão orientando quanto à adequação do rumo e escopo ${ }^{4}$. Ademais, é importante que revistas científicas, entre elas a Revista Brasileira de Cancerologia (RBC), mantenham um canal aberto para a divulgação da produção nessa área, propiciando a construção crítica de conhecimento específico e fornecendo elementos para o aprimoramento das açóes de controle do câncer.

\section{REFERÊNCIAS}

1. Ministério da Saúde (BR), Gabinete do Ministro. Portaria no 874, de 16 de maio de 2013. Institui a Política Nacional para a Prevenção e Controle do Câncer na Rede de Atenção à Saúde das Pessoas com Doenças Crônicas no âmbito do Sistema Único de Saúde (SUS). Diário Oficial da União, Brasília, DF; 2013 maio 17. Seção I, p. 129.

2. Paim J. O que é o SUS. Rio de Janeiro: Fiocruz; 2009.

${ }^{1}$ Instituto Nacional de Câncer José Alencar Gomes da Silva (INCA). Rio de Janeiro (RJ), Brasil. Orcid iD: https://orcid.org/0000-0002-2472-3444 Endereço para correspondência: Jeane Tomazelli. Rua Marquês de Pombal, 125, 70 andar - Centro. Rio de Janeiro (RJ), Brasil. CEP $22230-240$. E-mail: jtomazelli@inca.gov.br 
3. Hartz ZMA. Explorando novos caminhos na pesquisa avaliativa das açôes de saúde. In: Hartz ZMA organizador. Avaliação em saúde: dos modelos conceituais à prática na análise da implantação de programas. Rio de Janeiro: Fiocruz; 1997. p. 19-28.

4. Ministério da Saúde (BR), Secretaria de Vigilância em Saúde, Departamento de Análise de Situação de Saúde. Guia metodológico de avaliação e definição de indicadores: doenças crônicas não transmissíveis e Rede Carmen. Brasília, DF: Ministério da Saúde; 2007. (Série A. Normas e manuais técnicos).

5. Donabedian A. La Calidad de la atención médica. Rev Calid Asist. 2001;16:S29-S38.

6. Habicht JP, Victoria CG, Vaughan JP. Evaluation designs for adequacy, plausibility and probability of public health programme performance and impact. Int J Epidemiol. 1999;28(1):10-8. doi: https://doi.org/10.1093/ije/28.1.10

7. Santos IS, Victora CG. Serviços de saúde: epidemiologia, pesquisa e avaliação. Cad Saúde Pública. 2004;20(Supl 2):S337-41. doi: https://doi.org/10.1590/S0102-311X2004000800027 